\title{
Dates for Neanderthal art and symbolic behaviour are reliable
}

To the Editor - A News \& Views by Pearce and Bonneau ${ }^{1}$ published in Nature Ecology \& Evolution comments on recently published uranium-series age constraints for Cueva de los Aviones ${ }^{2}$, and for Palaeolithic cave paintings in three Spanish cave sites ${ }^{3}$. The authors query the reliability of the results in their discussion of stratigraphy between dated material and archaeological layers in Cueva de los Aviones; how dated crusts form on top of cave paintings; and our use of minimum ages to constrain the art. Here we comment on these issues and provide clarification.

Pearce and Bonneau ${ }^{1}$ emphasize the importance of understanding the relationship between materials available to be dated and materials of interest, where direct dates are not possible. However, for Cueva de los Aviones, they misinterpret the relationship between the dated flowstone (materials being dated) and the associated anthropogenic deposits (archaeological materials of interest) in suggesting that the dated flowstone may not originally have capped the archaeology. In fact, we discuss this issue in Hoffmann et al. ${ }^{2}$. After excavation ended in Cueva de los Aviones, a full profile was left intact including all layers as shown in Figs. 1C,D, 2 and S2 of Hoffmann et al. ${ }^{2}$. The stratigraphic position of the flowstone is described in the original excavation reports ${ }^{4,5}$ and in the original publication of the site's perforated shells and pigments ${ }^{6}$. The flowstone is interstratified in the anthropogenic deposit, not found in a higher level. It caps the levels excavated in 1985 that yielded the material of interest, and is in turn overlain by deposits that were not excavated because they are reduced to remnants adhering to the cave wall, as can be seen in Figs. 1C and $\mathrm{S} 3$ of Hoffmann et al. ${ }^{2}$. At the time of sampling, the profile was again inspected at the site and the stratigraphic relationship confirmed. The sampled specimen also shows that the flowstone and underlying sediment are interstratified at the contact zone, as illustrated in Figs. 4, S4 and S7 of Hoffmann et al. ${ }^{2}$. This can be the case only when the sediments as we find them today were already in place when the flowstone formed on top of them and thus unambiguously provides a minimum age for the accumulation of the sediments.

Pearce and Bonneau ${ }^{1}$ also ask why such a wide range of dates was determined on crusts overlying single motifs in Hoffmann et al. ${ }^{3}$. Simply, this is because we dated the ages at which speleothems were forming. There is absolutely no reason why independent speleothem formations within a cave should all be the same age, even if they are in close proximity (Fig. 1). In the case of La Pasiega, the two formations highlighted by Pearce and Bonneau ${ }^{1}$ are not a continuous flowstone layer but rather individual cauliflower-type crusts about $40 \mathrm{~cm}$ apart (Fig. 1a) - see Figs. S3, S4 and S5 of Hoffmann et al. ${ }^{3}$. At Maltravieso, the hand stencil (GS3b) is almost completely covered by a composite of many individual crusts (Fig. 1b), so sampling at different locations is likely to yield different uraniumthorium dates, consistent with the minimum age of the art. Individual cauliflower formations, even when in close proximity, cannot be expected to have formed simultaneously - they are distinct entities.

Finally, Pearce and Bonneau question our emphasis on the earliest dates obtained. Of course all dates must be considered in the chronological analysis, but when a dataset consists exclusively of minimum ages, it is entirely logical that the relevant motif was created before the oldest minimum age. To claim that the art could be any younger would be to disregard the oldest date, for no reason, and to disregard certain dates in a dataset would be unscientific.
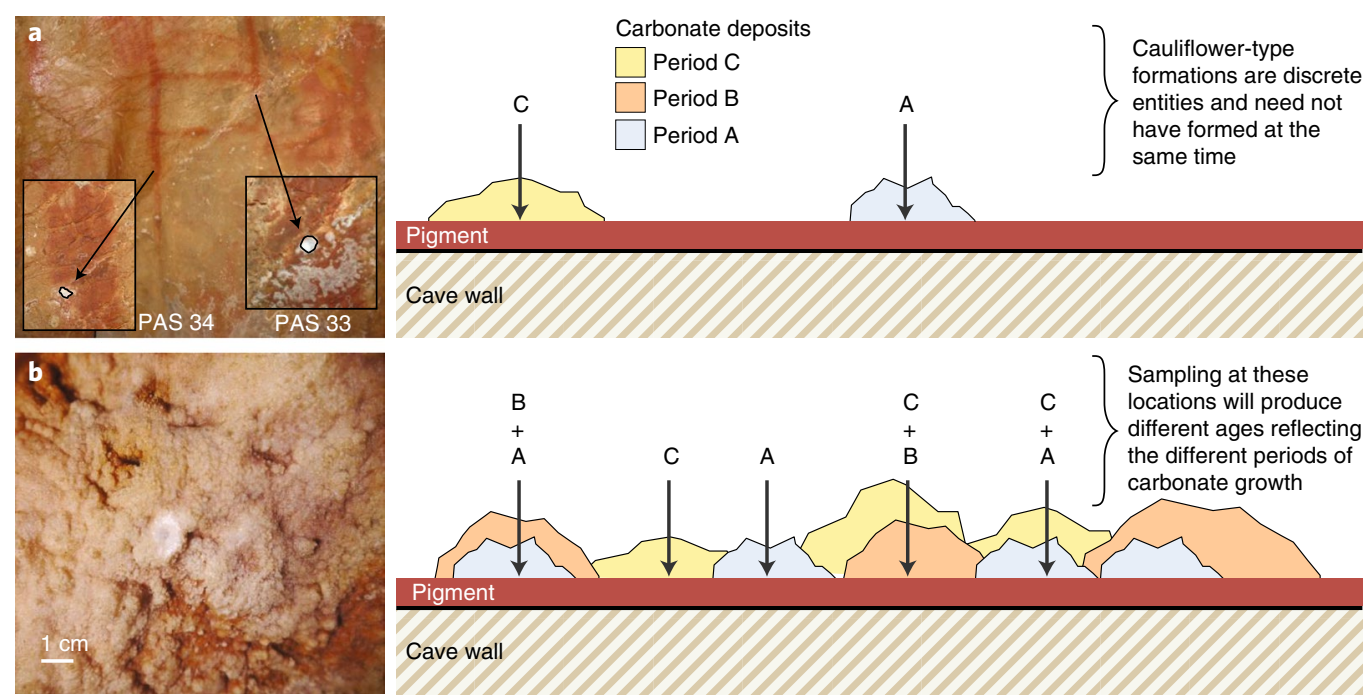

Fig. 1 | Schematic of formation of 'cauliflower' speleothems of different ages ( $A, B$ and $\mathbf{C}$ ) on top of a paint layer. $\mathbf{a}$, Where 'cauliflower' formation is discrete, for example at La Pasiega, different ages will be obtained for different phase 'cauliflowers'. b. Where 'cauliflower' formation is extensive, for example on Maltravieso hand stencil GS3b, the calcite deposit can become continuous, yet sampling at different locations will yield different dates. All will be consistent with the oldest minimum age obtained for the painting. 
The interpreted age of the art must satisfy all of the minimum ages with which it is associated. None of them can be excluded simply because they are different to proximal - but crucially unassociated speleothem formations.

In the case of Ardales, the fact that one painting has a wide range between minimum and maximum ages is irrelevant. Two red paintings have minimum ages older than 45,000 years ago (ka) and another has a minimum age of $65.5 \mathrm{ka}$. With current evidence for earliest modern human occupation of the Iberian Peninsula around $42 \mathrm{ka}$ (ref. ${ }^{7}$ ), our results from Ardales, Maltravieso and La Pasiega are surely enough of a 'smoking gun' to demonstrate that Neanderthals painted caves.

Dirk L. Hoffmann ${ }^{1 \star}$, Christopher D. Standish², Alistair W. G. Pike ${ }^{2 \star}$, Marcos García-Diez ${ }^{3}$, Paul B. Pettitt ${ }^{4}$, Diego E. Angelucci ${ }^{5}$, Valentín Villaverde ${ }^{6}$, Josefina Zapata7, James A. Milton ${ }^{8}$, Javier Alcolea-González ${ }^{9}$, Pedro Cantalejo-Duarte ${ }^{10}$, Hipolito Collado ${ }^{11}$, Rodrigo de Balbín' ${ }^{9}$ Michel Lorblanchet ${ }^{12}$,
José Ramos-Muñoz ${ }^{13}$, Gerd-Christian Weniger ${ }^{14,15}$ and João Zilhão ${ }^{16,17,18 *}$

${ }^{1}$ Department of Human Evolution, Max Planck Institute for Evolutionary Anthropology, Leipzig, Germany. ${ }^{2}$ Department of Archaeology, University of Southampton, Southampton, UK. ${ }^{3}$ Faculty of Humanities and Social Sciences, University of Isabel I, Burgos, Spain. ${ }^{4}$ Department of Archaeology, Durham University, Durham, UK. ${ }^{5}$ Dipartimento di Lettere e Filosofia, Università degli Studi di Trento, Trento, Italy. ${ }^{6}$ Departament de Prehistòria i d'Arqueologia, Universitat de València, València, Spain. 'Área de Antropología Física, Facultad de Biología, Universidad de Murcia, Murcia, Spain. ${ }^{8}$ Ocean and Earth Science, University of Southampton Waterfront Campus, National Oceanography Centre Southampton,

$\square \quad$ Southampton, UK. ${ }^{9}$ Prehistory Section, University of Alcalá de Henares, Madrid, Spain. ${ }^{10}$ Centro de la Prehistoria/Cueva de Ardales, Ardales, Málaga, Spain. ${ }^{11}$ Quaternary-Prehistory Research Group, I-PAT Research Group, D.G. Bibliotecas, Museos y Patrimonio Cultural, Junta de Extremadura, Spain. ${ }^{12}$ CNRS, Roc des Monges, St Sozy, France. ${ }^{13}$ Departamento de Historia, Geografía y Filosofia, Universidad de Cádiz, Cádiz, Spain. ${ }^{14}$ Neanderthal
Museum, Mettmann, Germany. ${ }^{15}$ Institute of Prehistory, University of Cologne, Cologne, Germany. ${ }^{16}$ Departament d'Història i Arqueologia (SERP), University of Barcelona, Barcelona, Spain. ${ }^{17}$ Institució Catalana de Recerca i Estudis Avançats (ICREA),

Barcelona, Spain. ${ }^{18}$ Centro de Arqueologia da Universidade de Lisboa (UNIARQ), Faculdade de Letras, Lisbon, Portugal.

*e-mail:dirk_hoffmann@eva.mpg.de; A.W.Pike@ soton.ac.uk; joao.zilhao@ub.edu

Published online: 25 June 2018

https://doi.org/10.1038/s41559-018-0598-Z

References

1. Pearce, D. G. \& Bonneau, A. Nat. Ecol. Evol. https://doi. org/10.1038/s41559-018-0540-4 (2018).

2. Hoffmann, D. L., Angelucci, D. E., Villaverde, V., Zapata, J. \& Zilhão, J. Sci. Adv. 4, eaar5255 (2018).

3. Hoffmann, D. L. et al. Science 359, 912-915 (2018).

4. Montes, R. El Paleolítico Medio en la costa de Murcia. PhD thesis, Univ. Murcia (1987).

5. Montes, R. Memorias de Arqueología de la Región de Murcia 2, $35-58$ (1991)

6. Zilhão, J. et al. Proc. Natl Acad. Sci. USA 107, 1023-1028 (2010).

7. Wood, R. E. et al. J. Hum. Evol. 69, 91-109 (2014)

Competing interests

The authors declare no competing interests. 